\title{
An evidence-based case for quality online initial teacher education
}

\author{
Lina Pelliccione, Valerie Morey, Rebecca Walker, Chad Morrison \\ Curtin University, Australia
}

\begin{abstract}
The rapid expansion of fully online delivery of initial teacher education (ITE) seen in the past decade has generated some concerns about impact on teacher quality. This is set within broader, sustained concerns about ITE generally. Much of the criticism of online ITE has been made without sufficient evidence to support the claims, largely due to the still-nascent evidence base. The data presented here contributes to that evidence base by providing demographic and academic achievement insights for cohorts of graduate teachers $(N=2008)$ across the years 2012 to 2018 who have engaged in fully online ITE at an Australian university. The literature has recognised the traditional barriers to accessing higher education for many of these students, including women, the mature-aged, and those with family and work responsibilities. Performance data for online ITE students within their programs demonstrates that they are breaking through these barriers associated with the digital divide. Analysis of who these people are, where they come from, and how they are performing provides valuable insights into online ITE, at a time when the value of broadening access to education and digital equity are being widely acknowledged.
\end{abstract}

Implications for practice or policy:

- The educational community should consider the achievement of online ITE students and contributions they can make to education and schools.

- The educational community should consider the contributions online ITE can make to broadening access to higher education and digital equity.

Keywords: online education, initial teacher education, digital equity, academic achievement, professional experience, student demographics

\section{Introduction}

Sustained concerns about the quality of Australian initial teacher education (ITE) abound within political discourse (see Stokes, 2018) and underpin current drivers for policy reform to strengthen ways of preparing teachers for contemporary classrooms (Teacher Education Ministerial Advisory Group, 2014). This ongoing critique has recently evolved to encompass a focus on the quality and performance of online ITE. Some concern is connected to the increased rate of online engagement that has occurred over the past decade (Australian Institute for Teaching and School Leadership [AITSL], 2018). This mode of engagement in ITE is relatively new, due to rapid advances in technology and digital communications. These advances have seen online enrolments increase by $11 \%$ since 2006 to $25 \%$ of total ITE enrolments in 2015 (AITSL, 2017). Over the same period, the rate of on-campus engagement of ITE students has fallen by $17 \%$ to $60 \%$ of total ITE enrolments. In addition, more students are engaging in blended modes of oncampus learning. This rapid change in the way that students engage in ITE has some observers very worried (see Stokes, 2018), and has also been reported within literature as being grounds for concern for some involved with the provision of ITE (Downing \& Dyment, 2013; Kehrwald \& McCallum, 2015; Mills, Yanes, \& Casebeer, 2009; Thornton, 2013).

Despite these contemporary concerns about online ITE and its perceived negative impact on graduate teacher quality, emerging evidence highlights the important contributions that online ITE is making to the preparation of teachers from diverse backgrounds and for diverse communities, and as a force for change towards greater equity of access for marginalised groups. Emerging data is illustrating that graduate teachers who have studied online perform well during their studies. Up until now, the absence of empirical evidence relating to the pedagogy, practices, and outcomes of online ITE has contributed to uncertainty about its contributions and value (AITSL, 2018); however, the data in this study contributes to a strong case for those previous perceptions to be revisited. Until recently, research of online ITE courses focused mostly on single units of study within a course and not on courses in their entirety nor on the full extent of 
outcomes of these units or courses. What is evident through an analysis of emerging course-level data is the need for a more complete and accurate understanding of the demographic profiles of those studying online and quantifiable data about their achievements and outcomes at the point of graduation and beyond.

\section{Background}

There has been a dramatic increase in students engaging in online degrees across courses and institutions around the world since their inception in the 1990s (Khoo, Forret, \& Cowie, 2014). Most forms of distance learning are now characterised by either partially or fully online modes of delivery. The need for student flexibility and the greater competition amongst higher education institutions are some key factors driving the popularity of online modes of study (de Freitas, Morgan, \& Gibson, 2015; Ragusa \& Crampton, 2017). Online courses utilise technologies to enable students to access synchronous and asynchronous learning opportunities and materials at times that suit them, while also being part of a community of practice (Clarke, 2009) to scaffold their own and their peers' knowledge through the course.

Improvements in the capacity of technologies have facilitated greater accessibility to online learning, whilst social change is demanding that access to higher education be universally equitable (Commonwealth of Australia, 2009). In Australia, there has been a massive expansion of online higher education, making it possible, in many cases, for students from more diverse backgrounds to study for the first time (O'Shea, Stone, \& Delahunty, 2015). An Australian university explained the diversity of their students and reported that $73 \%$ of their online students are mature age females, $43 \%$ of their online students are the first in their family to attend university, $48 \%$ have dependent children and $61 \%$ are working more than 30 hours a week (Lambrinidis, 2014).

Students opting to study ITE online in Australia are surpassing the growth pattern of online higher education both nationally and internationally. In 2016, online ITE courses were observed as growing at a rate six times faster than any other online course in the country, with 22,100 students (or 25\% of all ITE students) studying fully online (AITSL, 2018, p. 5). Of this cohort, about one third are studying at a university that is not in their state or territory of residence (AITSL, 2018). Notwithstanding this substantial differential in uptake trends, research in this specific sector has lagged behind that of research into online higher education in general. As such, the literature reviewed in this article will include both online ITE specifically as well as online higher education more broadly.

\section{Diverging perspectives about online higher education and ITE}

Whilst online ITE has been embraced by increasing numbers of pre-service teachers (AITSL, 2018), it continues to attract some critical views within the wider community. The rise of online ITE has resulted in a diversity of opinions and experiences about its effectiveness. There is general division amongst many academics about whether or not it is possible or appropriate to prepare students for teaching in an online environment (Downing \& Dyment, 2013; Kehrwald \& McCallum, 2015; Thornton, 2013). Some academics have expressed their distrust for the validity of online learning and concern for professional learning of students (Mills et al., 2009; Thornton, 2013). Further, academics have reported that students lack sufficient opportunity for observational modelling related to preparing to teach (Thornton, 2013).

Studies also suggest that employers show bias towards hiring graduates who have completed a traditionally orientated on-campus mode of study over those who chose online engagement and tend to show negative attitudes towards online education in general (Carnevale, 2007; Gaytan, 2009; Huss, 2007). Amongst other concerns, graduates of online courses are perceived as being less well-developed in the communication skills highly desired by employers (Carnevale, 2007; Gaytan, 2009; Huss, 2007). These perceptions are reflected within current statements and a policy shift in New South Wales that differentiates graduates on the basis of delivery mode (NSW Education Standards Authority, 2018). This article will argue that such positions fall short of adequately understanding the profile of learners within online ITE programs, the quality of their experiences, and the contributions that they are making to schools and communities once entering the workforce.

As educators have made their way into the online teaching space, some have reported that teaching online has effected a positive change in their on-campus teaching, which have become more blended, thereby generating further online resources for all of their students (Stacey \& Wiesenberg, 2007). They have 
reflected that whilst working online results in an increased workload, they became more disciplined, better organised, and more reflective and innovative with all their teaching practices (Stacey \& Wiesenberg, 2007). This transition to blended and online teaching has also resulted in improved communications and relationships with students more generally (Kehrwald \& McCallum, 2015). Importantly, blended and online teaching and learning in ITE is also informing pedagogy and practice in ways that are positively impacting on pre-service teachers' participation, engagement, and outcomes (Hunt, 2015). New ways of understanding the impact of technology-enhanced teaching and learning are also being coupled with insights into how learners respond and contribute to their own learning in powerful new ways (OttenbreitLeftwich, Glazewski, Brush, Aslan, \& Zachmeier, 2018).

\section{Broadening access to higher education and ITE}

Students are reshaping the higher education landscape as more choose study modes and availabilities that enable them to meet existing commitments alongside their studies. Those choosing online study in general, and ITE courses in particular, are contributing significantly to this reshaping. This shift has been facilitated in part by the Australian Government's agenda to increase participation in higher education, specifically for those groups traditionally locked out, including students from low socio-economic status (SES) backgrounds (Commonwealth of Australia, 2009). In response, most major higher education institutions around Australia now offer some form of online delivery within their ITE courses. The literature has reported that students choosing to study online ITE have similar demographics to the general online higher education population in that they are more likely to be of mature age, in the paid workforce, and female. Studies have reported that online ITE students reside in diverse geographical locations across Australia (Tomas, Lasen, Field, \& Skamp, 2015). Dyment, Downing, Hill, and Smith (2018) identified that online students were more likely to be mature-aged, female, in the paid workforce, have various family commitments, reside in regional and rural locations, and are located in lower socio-economic areas. In a study conducted by Heirdsfield, Davis, Lennox, Walker, and Zhang (2007), the majority of online ITE students resided in a regional area. Stone's (2012) findings contradicted those presented in online ITE in that the majority of online students reside in a major capital city in Australia. Nevertheless, these shared characteristics include many of those associated with the digital divide (Thomas et al., 2018).

Online students explain their choice to study in this delivery mode in a variety of ways, including the flexibility, convenience, and accessibility it offers, the self-paced learning, and also perceptions that online study is easier to navigate than on-campus engagement (He, 2014; Heirdsfield et al., 2007; Stone, 2012). The flexibility and increasing access to online technology widen the modes of learning and choices to a greater number of students, who are able to balance work, family, and other responsibilities at the same time as completing university studies (Stone, O'Shea, May, Delahunty, \& Partington, 2016). Online ITE has the capacity to promote and enhance digital equity, particularly in open units, which can provide greater access to these courses. These units provide academic and social spaces for students to build capacity with digital technologies, learning platforms, and software with peers who possess similar skills and knowledge upon course entry. Providing access and generating engagement in carefully scaffolded ways through online courses is therefore implicated in the outcomes of those courses. The nature of engagement in online learning can equip those students with technological knowledge and skills, which can positively impact their personal lives, study, and careers (Restal \& Laferrière, 2015). Stone et al. (2016) discussed the widening participation that online higher education affords students from diverse backgrounds, and particularly open-entry courses, which offer students from non-traditional backgrounds tertiary entrance pathways, improved access, and opportunities to higher education. Importantly, the ways in which this engagement in higher education equates to quality outcomes is firmly attached to how the Australian Government seeks to measure quality (Department of Education and Training, 2017). There are many persistent barriers to broadening participation in the Australian context (Meuleman, Garrett, Wrench, \& King, 2014; Wood, Gray-Ganter, \& Bailey, 2016); therefore, capturing emerging data about what is working within online ITE for the diverse student cohort that is choosing this pathway, why it is working for them, and addressing factors of social inequality is of critical importance to the ways that online ITE continues to evolve.

\section{Outcomes associated with online higher education and ITE}

The quality and rigour of online higher education and online ITE continue to be scrutinised, and claims have been made without evidence. The online delivery mode is often viewed as lesser than the on-campus 
delivery mode. In a meta-analysis conducted by Jahng, Krug, and Zhang (2007) examining published research that compared online post-secondary education and face-to-face education, no significant difference was found in student achievement between these delivery modes. Heirdsfield et al. (2007) reported that online and on-campus students shared similar learning experiences in early childhood education online units. From the perspective of schools in New South Wales, a study of 4202 online ITE student teachers on their professional experience placement found that school principals anecdotally reported they could not tell the difference between student teachers who had studied face to face or online (Board of Studies, Teaching and Educational Standards New South Wales, 2014). McMahon and Thompson (2014) interviewed 26 online ITE students before and after their practical teaching experience. Their data suggested the online ITE students were feeling confident in their teaching knowledge and skills and ready to be teachers.

Eom, Wen, and Ashill (2006) and Dyment and Downing (2018) reported that online higher education can be the superior mode of delivery if critical provisions such as accessible technologies and timely instructor feedback are met. Dyment and Downing (2018) detailed a study which utilised web conferencing to support the development of ITE professional attributes through professional conversations. ITE students reported deeper levels of engagement and satisfaction than other activities, including tutorials conducted in a faceto-face mode. Further, Pittaway and Moss (2014) have looked in detail at the experiences of online students. They reported that initially students feel overwhelmed and unsure, but as they move through the course, most students experience positive growth in their confidence and self-esteem and perform better than faceto-face students in many cases, as reported by O'Shea et al. (2015).

Castle and McGuire (2010) provided more evidence that student learning and satisfaction are less dependent on delivery mode per se and more dependent on other factors, such as technologies employed and instructional design. Another study, conducted by Paechter, Maier, and Macher (2010), involved 2196 students from 29 universities in Austria, examining their expectations and experiences of studying units online. The results of this research revealed that tutors' expertise in online learning and their support for student learning in this context were most predictive of student achievement and satisfaction. A systematic review conducted by Broadbent and Poon (2015) reported that online student self-regulation strategies, such as time management and critical thinking, were positively related to academic outcomes. Therefore, in examining online education, analysis must carefully consider multiple factors within the delivery mode before any evidential claims can be made.

\section{Methodology}

Enhanced knowledge of measures of engagement, achievement, and outcomes through online ITE are critical to understanding the impact that this delivery mode may be having on graduate teachers. This research aimed to examine online ITE through enhanced understandings about students engaging in this mode of study through examining demographic information and their academic achievement at course completion. Specifically, the research aimed to illustrate:

- demographic profiles of fully online ITE students, including their locations and factors associated with selecting online engagement as their preferred option; and

- achievement data, captured at course completion in the form of course weighted average (CWA) and final professional experience (FPE) percentage result, from successive cohorts of fully online pre-service teachers from 2012 to 2018.

\section{Research design and participants}

Case studies are often utilised to study a phenomenon in a real-life context (Grauer, 2012) and accommodate for the use of multiple forms of data collection (Yin, 2018). As such, a single case study design was employed in this research to undertake a comprehensive investigation of online ITE students within a school of education in an Australian university. The case study approach was descriptive and aimed to present an account of the phenomenon under study (Merriam, 1998).

The research setting was an Australian university which is a large ITE provider for fully online courses (AITSL, 2018). The participants comprised a purposive sample of convenience and were fully online ITE students completing their Bachelor of Education (Early Childhood) and Bachelor of Education (Primary 
Education) degrees in the years 2012 to 2018 in the School of Education through its external partner. These degrees are Australian Qualifications Framework Level 7, four-year, professionally accredited ITE courses with the last unit being the FPE. There are multiple entry pathways to these degrees, with students satisfying one of the following:

- the successful completion of four level one ITE units which are nominated as open to study for all;

- $\quad$ successful completion of two open level one ITE units plus evidence of English competency;

- $\quad$ successful completion of four undergraduate (or higher) units at an Australian university;

- Australian Tertiary Admission score of 70 or greater with English, English Literature or English as an Additional Language;

- $\quad$ successful completion of identified vocational diplomas and certificates with English competency (or higher);

- $\quad$ successful completion of the Special Tertiary Admissions Test in identified elements; or

- recognised Australian university enabling or bridging degrees.

Participants were located in all Australian states and territories $(N=2008)$, with 21 of them located outside of Australia. All data was de-identified and aggregated to ensure anonymity of participants. University approvals were gained to collect, analyse, and report on the de-identified data.

\section{Data collection}

The demographic and achievement data were collected across the years 2012 to 2018 for graduating students in each of these years. Within these years, there were four data collection points to coincide with the four study period course completion times. This totalled 28 data collection points. The data was collected via university student database and data management systems - these being Student One, Business Intelligence Tool, and the professional experience database system SONIA.

The demographic data collected included gender (female/male); age (years); SES (low, middle, high, other); and location of residence (urban, regional, remote, other) at time of course completion. Additional demographic data was collected, but as individuals could potentially be identified, this data is not reported.

Within the university systems, the SES definition is based on the Australian Bureau of Statistics (ABS) definition. The SES is referred to as a ranking system to explain a student's social and economic well-being based on their residing region (ABS, 2016b). The ranking is derived from multiple measures within the Population and Housing Australian Census (ABS, 2016b). The SES reported in this research is based on the student's home address at course completion using the ABS postcode classification. The four SES categories are low, middle, high, and other. A low SES is assigned if the student's percentile score is $\leq 25$, middle if the percentile is $>25$ and $<75$ and high if the percentile is $\geq 75$. The other classification is utilised for this research to describe international students, unknown postcode values and data not entered.

The residing location is a university description of the student's home address location at course completion, in accordance with the categories urban, regional, remote, and other. These categories are based on the ABS postcode classification (ABS, 2016a). The urban, regional, and remote classifications are for domestic students. The category other is used in this research to classify international students, unknown postcodes, data not entered, and undefined citizenship status.

The achievement data collected comprised CWA at course completion (percentage score) and FPE placement result (percentage score). The CWA is a weighted average percentage score that defines how well a student has performed in studying the course. The FPE is a full-time placement of one school term's duration in a school setting with students and is referred to within the university as the internship. The FPE is awarded a percentage score derived by averaging the percentage mentor teacher rating and the percentage supervisor rating. The FPE result is the student's first attempt score, inclusive of fail scores and zero scores awarded in situations such as withdrawal from the placement.

Additionally, the 2018 employment status of participants was included in the data collected. This information is collected by the university external partner through unit enrolment processes and reports on 
students enrolled in 2018 in at least one unit in the field of education delivered through the university's School of Education in a fully online mode $(N=4858)$. It is included to provide a further insight into the profiles of fully online ITE students. This data is provided by the fully online students in accordance with the categories reported in the Results section.

\section{Data analysis}

The demographic and achievement data collected from the three university systems was firstly collated into one database in the form of an Excel spreadsheet. Missing data was then identified and sought. In cases where the data could not be sourced, the participants' information was removed. Once the database was complete, data was then de-identified. Following this, student numbers, CWA, and FPE mean averages and standard deviations were calculated for each year, and according to age (in groups $<25,25-39, \geq 40$ years), SES, and residing location. Differences in CWA and FPE means according to age, SES, residing location, and year were determined along with effect sizes using Cohen's $d$. The effect size of 0.2 was interpreted as small, 0.5 as medium, and 0.8 as large (Cohen, 1988). Whole cohort correlational analysis between CWA and FPE were conducted.

The 2018 employment status of participants is reported separately as a percentage score. This data was categorised, collected, and analysed by the university's external partner. The categories were full-time employed, part-time employed, self-employed, employed in family business, home duties, employer, fulltime student, seeking full-time work, seeking part-time work, unemployed nor seeking work, and not applicable. Students could assign themselves to only one category.

\section{Results}

The demographic data and relating CWA and FPE scores across the years 2012 to 2018 will be reported according to the categories of gender, age, SES, and residing location. Following this, differences in means for years, gender, age, SES, and residing location will be identified. This aims to identify patterns in demographics and achievement. In order to understand the whole cohort of participants $(N=2008)$, the overall mean average for CWA and FPE and the correlation between them are reported in Table 1.

Table 1

Participant CWA and FPE mean and standard deviation

\begin{tabular}{llll}
\hline Score & Mean & SD & Correlation \\
\hline CWA & 71.29 & 6.11 & $0.35^{*}$ \\
FPE & 83.14 & 12.93 & \\
\hline${ }^{*} p<0.05, N=2008$ & &
\end{tabular}

The bivariate Pearson correlation analysis (two-tailed) conducted determined there was a statistically significant moderate correlation between the CWA and FPE for the whole participant cohort across all years 2012 to 2018 as reported in Table 1 .

\section{Gender}

The gender profile of participants (female and male only) across all years 2012 to 2018 was $91 \%$ female and 9\% male students. The participants' CWA and FPE mean and standard deviations according to gender are reported in Table 2.

Table 2

Participant CWA and FPE mean and standard deviation according to gender

\begin{tabular}{llccccc}
\hline Score & Gender & $\boldsymbol{n}$ & Mean & $\boldsymbol{S D}$ & $\boldsymbol{T}$ & $\begin{array}{c}\text { Difference } \\
\text { Effect size Cohen's } \boldsymbol{d}\end{array}$ \\
\hline CWA & Female & 1825 & 71.31 & 6.12 & $2.66^{*}$ & 0.11 \\
& Male & 183 & 70.05 & 14.02 & & \\
FPE & Female & 1825 & 83.47 & 12.75 & $3.63^{*}$ & 0.27 \\
& Male & 183 & 79.80 & 14.20 & & \\
\hline
\end{tabular}


An independent-samples $t$ test was run to determine if there were differences between gender for both CWA and FPE mean scores. There was a homogeneity of variances for CWA mean scores, as assessed by Levene's test for equality of variances $(p=.294)$, and for FPE mean scores $(p=.513)$. A statistical difference between male and female CWA means was revealed, $M=1.26,95 \%$ confidence interval (C)I) [0.339 to 2.184], $t(2006)=2.659, p<.05$, and also for FPE means, $M=3.669,95 \%$ CI $[1.688$ to 5.650], $t(1972)=3.632, p<.05$. Effect size was then examined using Cohen's $d$, which revealed that the differences between female and male for both CWA and FPE scores were small effects.

\section{Age}

The age profile of participants $(<25,25-39, \geq 40)$ across all years 2012 to 2018 were $6 \%<25,62 \% 25-$ 39 , and $32 \% \geq 40$. The participants CWA and FPE mean and standard deviations relating to age are reported in Table 3.

Table 3

Participant CWA and FPE mean and standard deviation according to age

\begin{tabular}{lcccc}
\hline Score & Age & $\boldsymbol{n}$ & Mean & SD \\
\hline CWA & $<25$ & 129 & 69.49 & 5.88 \\
& $25-39$ & 1248 & 70.83 & 6.05 \\
& $\geq 40$ & 631 & 72.26 & 6.12 \\
FPE & $<25$ & 129 & 82.99 & 11.67 \\
& $25-39$ & 1248 & 83.57 & 12.77 \\
& $\geq 40$ & 631 & 82.32 & 13.45 \\
\hline
\end{tabular}

A one-way ANOVA was conducted to assess statistical differences between age and CWA, then age and FPE. In relation to CWA, there was homogeneity of variances, as assessed by Levene's test for equality of variances $(p=.566)$ and statistical difference was identified $F(2,2005)=17.06, p<.05$. Bonferroni post hoc analysis revealed that there was a range of statistical differences. The $<25$ age group CWA when compared to the $\geq 40$ age group CWA showed a mean difference of $2.77,95 \%$ CI [1.36, 4.17], which was statistically significant $(p<.05)$. A medium Cohen $d$ effect size was observed in this comparison at 0.46 . The 25-39 age group CWA in comparison to the $\geq 40$ age group CWA detailed a statistical significant ( $p$ $<.05)$ mean difference of $1.43,95 \%$ CI $[.718,2.13]$. Within this comparison, a small Cohen's $d$ effect size was found at 0.24 . There were no statistical differences between age and FPE.

\section{SES}

The SES of participants (low, middle, high, other) across all years 2012 to 2018 were $25 \%$ low, $57 \%$ middle, $17 \%$ high, and $1 \%$ other. The participants' CWA and FPE mean and standard deviations associated to SES are reported in Table 4.

Table 4

Participant CWA and FPE mean and standard deviation according to SES

\begin{tabular}{lcccc}
\hline Score & SES & $\boldsymbol{n}$ & Mean & SD \\
\hline CWA & Low & 493 & 70.68 & 5.92 \\
& Middle & 1140 & 71.32 & 6.09 \\
& High & 346 & 71.47 & 6.39 \\
FPE & Other & 29 & 71.32 & 6.06 \\
& Low & 493 & 81.90 & 13.00 \\
& Middle & 1140 & 83.56 & 12.76 \\
& High & 346 & 83.56 & 13.21 \\
& Other & 29 & 82.59 & 14.18 \\
\hline
\end{tabular}

One-way ANOVA was undertaken to determine differences between SES and CWA and between SES and FPE. However, there were no statistical differences found. 


\section{Residing location}

The residing locations of participants across all years 2012 to 2018 were $73 \%$ urban, $24 \%$ regional, $2 \%$ remote, and 1\% other. The participants' CWA and FPE mean and standard deviations relating to residing location are reported in Table 5.

Table 5

Participant CWA and FPE mean and standard deviation according to residing location

\begin{tabular}{lcccc}
\hline Score & Residing location & $\boldsymbol{n}$ & Mean & SD \\
\hline CWA & Urban & 1462 & 71.07 & 6.17 \\
& Regional & 489 & 71.35 & 5.75 \\
& Remote & 33 & 72.74 & 7.78 \\
& Other & 24 & 73.24 & 6.28 \\
\hline FPE & Urban & 1462 & 83.28 & 12.85 \\
& Regional & 489 & 82.86 & 13.05 \\
& Remote & 33 & 81.00 & 12.76 \\
& Other & 24 & 82.71 & 15.81 \\
\hline
\end{tabular}

One-way ANOVA was run to determine differences between residing location CWA and between CWA and FPE. However, there were no statistical differences found.

\section{Course completion year}

The course completion cohort for 2012 to 2018 CWA and FPE mean and standard deviations were calculated. These are reported in Table 6.

Table 6

Course completion cohorts 2012 to 2018 CWA and FPE mean and standard deviation

\begin{tabular}{lcccc}
\hline Score & Completion year & $\boldsymbol{n}$ & Mean & SD \\
\hline CWA & 2012 & 76 & 74.26 & 6.53 \\
& 2013 & 237 & 73.08 & 6.07 \\
2014 & 294 & 72.30 & 6.09 \\
2015 & 344 & 70.12 & 5.96 \\
& 2016 & 394 & 71.09 & 5.53 \\
& 2017 & 360 & 70.53 & 6.16 \\
& 2018 & 303 & 70.01 & 6.12 \\
\hline FPE & 2012 & 76 & 82.04 & 14.61 \\
& 2013 & 237 & 83.50 & 12.52 \\
& 2014 & 294 & 83.80 & 12.29 \\
& 2015 & 344 & 83.12 & 13.10 \\
& 2016 & 394 & 84.56 & 12.29 \\
& 2017 & 360 & 83.43 & 13.01 \\
& 2018 & 303 & 80.29 & 13.58 \\
\hline
\end{tabular}

To investigate patterns in difference in achievement across the years 2012 to 2018, a one-way ANOVA was conducted. This was used to assess statistical differences between year of completion and CWA and then between year of completion and FPE. In relation to the CWA, there was homogeneity of variances, as assessed by Levene's test for equality of variances $(p=.402)$ and statistical difference identified $f(6,2001)$ $=13.41, p<.05$. Bonferroni post hoc analysis revealed that there were a range of statistical differences. These are reported in Table 7. 
Table 7

CWA significant mean differences across years 2012 to 2018

\begin{tabular}{|c|c|c|c|c|}
\hline \multirow{2}{*}{$\begin{array}{l}\begin{array}{l}\text { Course } \\
\text { completion } \\
\text { year }\end{array} \\
2012 \\
\end{array}$} & \multicolumn{4}{|c|}{ Year significant difference CWA $M D$} \\
\hline & 2015 & 2016 & 2017 & 2018 \\
\hline & $M D=-4.15,95 \%$ & $M D=-3.17,95 \%$ & $M D=-3.73,95 \%$ & $M D=-4.25,95 \%$ \\
\hline & CI $[-6.46,-1.84]$ & CI $[-5.46,-.886]$ & CI $[-6.04,-1.43]$ & CI $[-6.59,-1.91]$ \\
\hline & $(p<.05)$ & $(p<.001)$ & $(p<.05)$ & $(p<.05)$ \\
\hline & Cohen's $d=0.66$ & Cohen's $d=0.52$ & Cohen's $d=0.59$ & Cohen's $d=0.67$ \\
\hline \multirow[t]{5}{*}{2013} & 2015 & 2016 & 2017 & 2018 \\
\hline & $M D=-2.96,95 \%$ & $M D=-1.98,95 \%$ & $M D=-2.54,95 \%$ & $M D=-3.06,95 \%$ \\
\hline & CI $[-4.50,-1.42]$ & CI $[-3.48,-.482]$ & CI $[-4.07,-1.02]$ & CI $[-4.64,-1.48]$ \\
\hline & $(p<.05)$ & $(p<.05)$ & $(p<.05)$ & $(p<.05)$ \\
\hline & Cohen's $d=0.49$ & Cohen's $d=0.34$ & Cohen's $d=0.42$ & Cohen's $d=0.50$ \\
\hline \multirow[t]{5}{*}{2014} & 2015 & 2016 & 2017 & 2018 \\
\hline & $M D=-2.18,95 \%$ & & $M D=-1.76,95 \%$ & $M D=-2.28,95 \%$ \\
\hline & CI $[-3.62,-.727]$ & & CI $[-3.19,-.327]$ & CI $[-3.77,-.786]$ \\
\hline & $(p<.05)$ & & $(p<.05)$ & $(p<.05)$ \\
\hline & Cohen's $d=0.36$ & & Cohen's $d=0.29$ & Cohen's $d=0.38$ \\
\hline
\end{tabular}

The significant differences between the 2012 course completion year CWA scores and 2015, 2016, 2017 , and 2018 observed a medium effect size. This also occurred for 2013 in comparison to 2015, 2017, and 2018 and for 2014 to 2015 and 2018. A small effect size was found in comparing 2013 and 2016 CWA and for 2014 and 2017. There were no identified significant statistical differences in comparing the CWA means across the years 2015 to 2018 .

With regards to the FPE, there was homogeneity of variances, as assessed by Levene's test for equality of variances $(p=.065)$ and statistical difference was identified $F(6,1967)=3.47, p=.02$. Bonferroni post hoc analysis revealed that the only statistical difference was between 2018 and the years 2014, 2016, and 2017. These are reported in Table 8 .

Table 8

FPE significant mean differences across years 2012 to 2018

\begin{tabular}{llll}
\hline Course completion year & \multicolumn{3}{c}{ Year significant difference FPE MD } \\
\hline 2018 & 2014 & 2016 & 2017 \\
& $M D=3.51,95 \%$ & $M D=4.27,95 \%$ CI & $M D=3.14,95 \%$ CI \\
& CI $[.27,6.75](p<$ & {$[1.24,7.30] \quad(p<$} & {$[.06,6.23](p<.05)$} \\
$.05)$ & $\begin{array}{l}.05) \\
\text { Cohen's } d=0.27\end{array}$ & Cohen's $d=0.27$ & \\
& & Cohen's $d=0.24$ \\
\hline
\end{tabular}

The significant differences between the 2018 course completion year CWA scores and 2014, 2016 and 2017 observed a small effect size. There were no identified significant statistical differences in comparing the FPE means across the years 2012 to 2017.

\section{Employment status}

The employment status of students in 2018, with at least 1 subject enrolment $(N=4858)$ delivered by the university's School of Education in a fully online mode, is presented in Figure 1. 


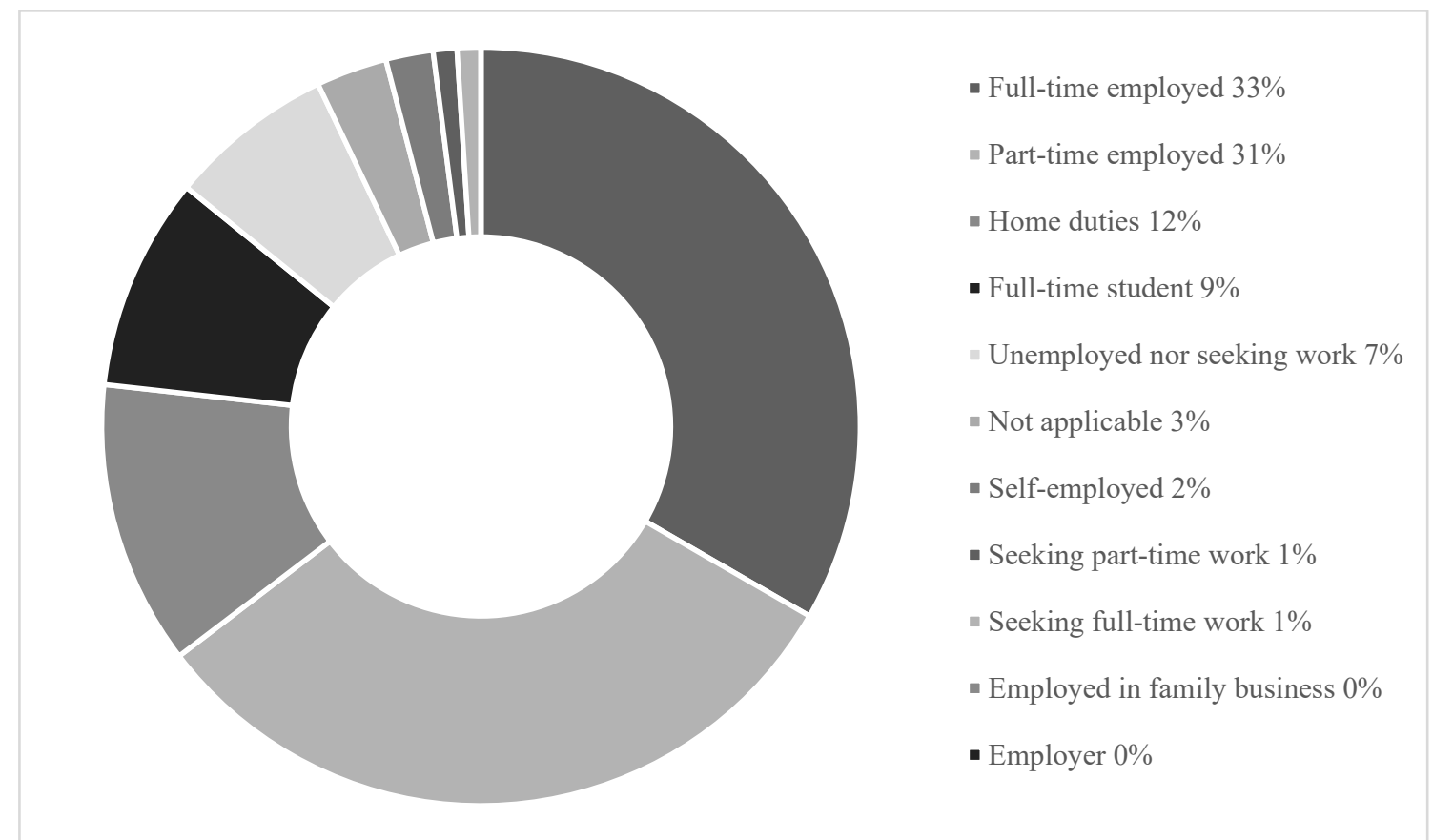

Figure 1. Fully online cohort employment status 2018

\section{Discussion}

This research aimed to examine and describe the profile of ITE students studying fully online at an Australian university. Data was collected through university systems, collated into a large database, and analysed. Analysis of results reflected existing literature, in that students entering ITE are predominately female (Tomas et al., 2015), aged 25 to 40 (Heirdsfield et al., 2007), residing in urban areas (Stone, 2012), and middle SES areas. What this analysis contributes to the literature is their academic achievement. Their CWA hovered around distinction level (approximately 70\%-80\%) and their performance in their FPE were consistently rated at high distinction (more than $80 \%$ ), with a positive correlation identified between them. These findings present a pattern of successful academic achievement within theory and practical application components of ITE, across a range of factors and years. These outcomes were achieved within the complex circumstances of mature-aged learning (Gall, Evans, \& Bellerose, 2000), with many of these students achieving strong outcomes whilst managing paid work, care responsibilities and home duties. This data challenges scepticism that may be felt towards the capacity of fully online ITE courses to adequately prepare classroom-ready teachers (King, 2002; Ouzts, 2006).

\section{Gender, age, and online ITE}

Of those participants completing an online ITE course during the data collection period, the overwhelming majority $(91 \%)$ were women $(n=1825)$. While $6 \%$ of the entire online cohort were younger than 25 years, the majority were aged between 26 and 39 years (61\%) with another $32 \%$ aged 40 years or older. This data reflects what is known about the complex lives these students live, regularly raising families and providing primary care for children and spouses, while often also informally and formally engaging with education settings while completing their studies (Beutel \& Crosswell, 2013; Richardson \& Watt, 2006). These experiences relating to gender and age provide further insights into the strength of CWA and FPE performance of these students. This graduate cohort demonstrated a consistent capacity to achieve strong outcomes across course components and time, despite the challenges of their personal circumstances beyond study. In these ways, online ITE provides the mode of study that allows for engagement and achievement.

\section{Location and access to ITE}

The fully online ITE courses at this university afford opportunities for students to effectively engage in higher education regardless of location. Data collected over a sustained period of 7 years demonstrates that 
regional and remote populations were able to study ITE and remain in their communities whilst doing so at performance and achievement levels comparable to their metropolitan peers. Whilst the residing location of the majority of pre-service teachers was located in urban districts, approximately $25 \%$ of this study's ITE student population lived in regional areas. This is similar to the national regional population, which was reported as being approximately $27 \%$ of the Australian population in 2011 (ABS, 2011). Similarly, the students completing an ITE course in a remote location accounted for $0.02 \%$, which is equivalent to the national population of $0.02 \%$ of Australians residing in a remote location (ABS, 2011). These consistent rates of enrolments from regional and remote students across years show a pattern of regional and remote Australians taking up higher education.

Of all participants, $73 \%(n=1462)$ of online ITE students within this study were located in urban settings. Many people living within urban settings, including within outer-urban settings and on the urban/regional fringe, identify online ITE as a mechanism for engaging in higher education.

Importantly, analysis revealed no statistical difference between residing location and CWA nor between residing location and FPE within these cohorts, despite the known challenges of studying ITE online (Muir et al., 2019). These results suggest that there is potential for these students to remain in these urban, regional and remote areas, fulfilling the needs of their local school communities (McDonnell et al., 2011).

\section{SES and access to ITE}

Online ITE provides accessibility to higher education for populations, despite the known barriers of SES (Stone et al., 2016). The provision of high-quality online teaching and learning for ITE students provides equitable access to those who, in many cases, would otherwise be unable to access it. Data analysed here identified 493 students from low-rated SES backgrounds who successfully completed their ITE course during the data collection period. Analysis of their academic results revealed successful academic achievement across their courses, including professional experience, with no significant mean differences in CWA and FPE between them and their 1486 peers from middle and upper SES backgrounds. While it is anticipated that low SES will be an influential factor in other analysis of online ITE (including attrition and time to completion), low SES is not evident in the performance outcomes of the target cohort at course completion.

\section{The significance of demographics within online ITE}

This article calls for a wider consideration of the data pertaining to online ITE. It aims to debunk the myths that online ITE does not prepare quality teachers and does not make meaningful contributions to communities and the teaching workforce more generally. It argues that ITE can be successfully delivered in an online mode. Further, it provides evidence that student demographics and life experiences result in successful ITE students who obtain high levels of achievement.

Analysis of data across residing location and SES reveals no statistical mean differences in CWA and FPE. This analysis emphasises that regardless of location and complexities associated with life, quality online ITE is a vehicle for equitable access to teaching futures. The data has the potential to disrupt perceptions about a correlation between downward trending of teacher quality and the trends reported by AITSL (2017) towards fewer students entering ITE courses with a high Australian Tertiary Admission score. These concerns were voiced widely in the media following the release of the AITSL report (The Guardian, 2018; SBS, 2018). However, not only do these fully online ITE courses respond to calls for capable graduates to enter the teaching workforce in Australia (Teacher Education Ministerial Advisory Group, 2014), they also provide some confirmation of the findings of Wright's (2015) study, which concluded that "the data suggest that a variety of selection methods and criteria are required and ensuring high standards within ITE courses is the best way to control for quality of graduates" (p. 1). These findings, combined with the numbers of students residing in regional and remote Australia, help to address the intent of policies and initiatives to enable greater accessibility to higher education (e.g., OECD, 2018) and the provision of quality ITE in these areas. Furthermore, these findings emphasise the contribution that online ITE is making to digital equity through these graduates successfully utilising technology and acquiring skills and knowledge to gain a higher education qualification. These outcomes are inherently good for graduates of fully online ITE courses as they are seen to improve their personal lives while also enhancing career opportunities (Restal \& Laferrière, 2015). Additionally, enhanced knowledge, skills and capacity to teach and learn with and 
through new technologies are fundamental to strengthening the Australian teaching workforce in this domain (Falkner \& Vivian, 2015), and this has significant implications for future teacher practice.

\section{Conclusion}

In recent times, the criticism of and bias towards online ITE have not considered who these students are nor their achievement in their courses. A range of data was collected and analysed to examine online ITE students' achievement and outcomes. The demographic profile of online students and their academic performance at course completion provides indicators of positive impact measures of success that warrant attention. Emerging from the study were demographic indicators that suggested motivations for commencing ITE are related to access and convenience, and that the outcomes associated with this engagement can be measured and reported in the form of high CWA and FPE results. Also revealed by the research was the significant insight that the cohorts of online ITE students investigated here often contending with several concurrent layers of complexity during their course. Despite the complexities faced outside of their online learning environment, their achievement data is compelling evidence that this did not impede their achievement. This emerging data emphasises that online ITE can and does support highly motivated and capable individuals and groups to pursue productive and accessible pathways into teaching. Moreover, they are engaged in social interactions and teaching and learning arrangements that support them to develop the knowledge and skills to perform in this online learning environment. This evidence also emphasises that these graduates are making important contributions to regional and remote communities and their local schools. These data sets also warrant consideration in relation to future policy development in this area and reconsideration of policies that exclude and hinder career opportunities for these graduates.

The database created in this study will continue to be populated to report on longitudinal patterns and trends (Bozkurt et al., 2015) with the inclusion of entry pathway data. The study also provides some focus for valuable further research, particularly for data about the employment and career outcomes of ITE students. The graduates of these online ITE courses are equipped with technological knowledge and skills, and as such, the examination of greater integration of technology into their future learning and teaching is an area of warranted exploration. These graduate teachers are entering the profession at the same time as Digital Technologies is being consolidated into the Australian curriculum (Australian Curriculum, Assessment and Reporting Authority (2014). Previous concerns have been raised about the knowledge, skills and capacity of the existing teacher workforce in this domain (Falkner \& Vivian, 2015); therefore, exploration of fully online ITE graduates' knowledge, skills and contributions to teaching in this area are all valuable considerations for future research. Additionally, further research may demonstrate whether these teachers contribute to the digital equity of those students who may have been previously excluded and how their preparation for teaching has the potential to reduce the digital divide for future learners. This data will provide broader-reaching evidence of online ITE quality through identifying these teachers' continuing contributions to education and communities. In addition, more exploration into effective online learning and teaching practices in ITE will provide reports that will guide best practice in the sector.

\section{Acknowledgements}

The grant fund contribution from the university's School of Education in which this research was conducted is acknowledged with gratitude.

\section{References}

Australian Bureau of Statistics. (2011). Estimates of Aboriginal and Torres Strait Islander Australians, June 2011. Retrieved from http://www.abs.gov.au/AUSSTATS/abs@.nsf/DetailsPage/3238.0.55.001June\%202011?OpenDocum ent

Australian Bureau of Statistics. (ABS) (2016a). Postal areas (POAs). Retrieved from https://www.abs.gov.au/ausstats/abs@.nsf/Lookup/by\%20Subject/1270.0.55.003 July\%202016 Mai

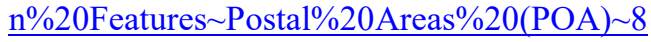

Australian Bureau of Statistics. (2016b). Socio-economic indexes for areas (SEIFA) 2016. Retrieved from https://www.abs.gov.au/ausstats/abs@.nsf/mf/2033.0.55.001 
Australian Curriculum, Assessment and Reporting Authority. (2014). Digital technologies. Retrieved from https://www.australiancurriculum.edu.au/f-10-curriculum/technologies/digital-technologies/

Australian Institute for Teaching and School Leadership. (2017). Initial teacher education: Data report 2017. Melbourne, Australia: Author. Retrieved from https://www.aitsl.edu.au/docs/defaultsource/research-evidence/ite-data-report/2017/ite-data-report-2017.pdf?sfvrsn=a33fe93c 8

Australian Institute for Teaching and School Leadership. (2018). Spotlight: The rise of online initial teacher education: what do we know? Melbourne, Australia: Author. Retrieved from https://www.aitsl.edu.au/docs/default-source/researchevidence/spotlight/spotlight ite online .pdf?sfvrsn $=22 \mathrm{a} 8 \mathrm{f} 73 \mathrm{c} 2$

Beutel, D., \& Crosswell, L. (2013, October). The long way round: Graduate entry preservice teachers' pathways into teaching. Paper presented at the TARC international conference on learning and teaching, Kuala Lumpur, Malaysia.

Board of Studies, Teaching and Educational Standards New South Wales. (2014). Online initial teacher education in NSW. Sydney, Australia: Author. Retrieved from https://educationstandards.nsw.edu.au/wps/wcm/connect/5002786d-744e-4d46-b688088f5f15906d/OnlineInitialTeacherEducationReportAccess.pdf?MOD=AJPERES\&CVID=

Bozkurt, A., Akgun-Ozbek, E., Yilmazel, S., Erdogdu, E., Ucar, H., Guler, E., ... Aydin, C. H. (2015). Trends in distance education research: A content analysis of journals 2009-2013. The International Review of Research in Open and Distributed Learning, 16(1), 330-363. https://doi.org/10.19173/irrodl.v16i1.1953

Broadbent, J., \& Poon, W. L. (2015). Self-regulated learning strategies \& academic achievement in online higher education learning environments: A systematic review. Internet and Higher Education, 27, 113. https://doi.org/10.1016/j.iheduc.2015.04.007

Carnevale, D. (2007, January 5). Employers often distrust online degrees. Chronicle of Higher Education. Retrieved from https://www.chronicle.com/article/Employers-Often-Distrust/34334

Castle, S. R., \& McGuire, C. J. (2010). An analysis of student self-assessment of online, blended, and face-to-face learning environments: Implications for sustainable education delivery. International Education Studies, 3(3), 36-40. https://doi.org/10.5539/ies.v3n3p36

Clarke, L. (2009). The POD Model: Using communities of practice theory to conceptualise student teachers' professional learning online. Computers \& Education, 52(3), 521-529. https://doi.org/10.1016/j.compedu.2008.10.006

Cohen, J. (1988). Statistical power analysis for the behavioral sciences. New York, NY: Routledge.

Commonwealth of Australia. (2009). Transforming Australia's higher education system. Canberra, Australia: Author. Retrieved from http://pandora.nla.gov.au/pan/109846/201307030929/www.innovation.gov.au/HigherEducation/Documents/TransformingAusHigherED.pdf

de Freitas, S. I., Morgan, J., \& Gibson, D. (2015). Will MOOCs transform learning and teaching in higher education? Engagement and course retention in online learning provision. British Journal of Educational Technology, 46(3), 455-471. https://doi.org/10.1111/bjet.12268

Department of Education and Training. (2017). The higher education reform package. Canberra, Australia: Commonwealth of Australia. Retrieved from https://docs.education.gov.au/system/files/doc/other/ed17-0138 - he - glossy budget report_acc.pdf

Downing, J. J., \& Dyment, J. E. (2013). Teacher educators' readiness, preparation and perceptions of preparing preservice teachers in a fully online environment: an exploratory study. Teacher Educator, 48(2), 96-109. https://doi.org/10.1080/08878730.2012.760023

Dyment, J. E., \& Downing, J. J. (2018). Online initial teacher education students' perceptions of using web conferences to support professional conversations. Australian Journal of Teacher Education, 43(4), 68-91. https://doi.org/10.14221/ajte.2018v43n4.5

Dyment, J., Downing, J., Hill, A., \& Smith, H. (2018). "I did think it was a bit strange taking outdoor education online": Exploration of initial teacher education students' online learning experiences in a tertiary outdoor education unit. Journal of Adventure Education and Outdoor Learning, 18(1), 70-85. https://doi.org/10.1080/14729679.2017.1341327

Eom, S. B., Wen, J. H., \& Ashill, N. (2006). The determinants of students' perceived learning outcomes and satisfaction in university online education: An empirical investigation. Decision Sciences Journal of Innovative Education, 4(2), 215-235. https://doi.org/10.1111/j.1540-4609.2006.00114.x

Falkner, K., \& Vivian, R. (2015). A review of computer science resources for learning and teaching with K-12 computing curricula: an Australian case study. Computer Science Education, 25(4), 390-429. https://doi.org/10.1080/08993408.2016.1140410 
Gall, T., Evans, D., \& Bellerose, S. (2000). Transition to first-year university: Patterns of change in adjustment across life domains and time. Journal of Social and Clinical Psychology, 19(4), 544-567. https://doi.org/10.1521/jscp.2000.19.4.544

Gaytan, J. (2009). Analyzing online education through the lens of institutional theory and practice: The need for research-based and -validated frameworks for planning, designing, delivering, and assessing online instruction. Delta Pi Epsilon Journal, 51(2), 62-75. Retrieved from https://www.learntechlib.org/p/68455/

Grauer, K. (2012). A case for case study research in education. In S.R. Klein (Ed.), Action research methods (pp. 69-79). New York, NY: Palgrave Macmillan.

He, Y. (2014). Universal design for learning in an online teacher education course: Enhancing learners' confidence to teach online. Journal of Online Learning and Teaching, 10(2), 283-298. Retrieved from http://jolt.merlot.org/vol10no2/he 0614.pdf

Heirdsfield, A., Davis, J., Lennox, S., Walker, S., \& Zhang, W. (2007). Online learning environments: What early childhood teacher education students say. Journal of Early Childhood Teacher Education, 28(2), 115-126. https://doi.org/10.1080/10901020701366699

Hunt, A. M. (2015). Blended online learning in initial teacher education: A professional inquiry into preservice teachers' inquiry projects. Journal of Open, Flexible and Distance Learning, 19(2), 48-60. Retrieved from http://www.jofdl.nz/index.php/JOFDL/article/view/245/195

Huss, J. A. (2007). Attitudes of middle grades principals toward online teacher preparation programs in middle grades education: Are administrators pushing "delete"? RMLE Online, 30(7), 1-13. https://doi.org/10.1080/19404476.2007.11462040

Jahng, N., Krug, D., \& Zhang, Z. (2007). Student achievement in online distance education compared to face-to-face education. European Journal of Open, Distance and E-Learning, 10(1). Retrieved from http://www.eurodl.org/materials/contrib/2007/Jahng_Krug_Zhang.htm

Kehrwald, B. A., \& McCallum, F. (2015). Degrees of change: Understanding academics experiences with a shift to flexible technology-enhanced learning in initial teacher education. Australian Journal of Teacher Education, 40(7). https://doi.org/10.14221/ajte.2015v40n7.4

Khoo, E., Forret, M., \& Cowie, B. (2014). Lecturer-student views on successful online learning environments. Waikato Journal of Education, 15(3). https://doi.org/10.15663/wje.v15i3.79

King, K. (2002). Identifying success in online teacher education and professional development. The Internet and Higher Education, 5(3), 231-246. https://doi.org/10.1016/S1096-7516(02)00104-5

Lambrinidis, G. (2014). Supporting online, non-traditional students through the introduction of effective e-learning tools in a pre-university tertiary enabling programme. Journal of Higher Education Policy and Management, 36(3), 257-267. https://doi.org/10.1080/01587919.2014.899053

McDonnell, J., Jameson, J. M., Riesen, T., Polychronis, S., Crockett, M. A., \& Brown, B. E. (2011). A comparison of on-campus and distance teacher education programs in severe disabilities. Teacher Education and Special Education, 34(2), 106-118. https://doi.org/10.1177/0888406410380424

McMahon, J. A., \& Thompson, M. (2014). Health and physical education and the online tertiary environment at two universities: Pre-service teachers' perceived "readiness" to teach HPE. Australian Journal of Teacher Education, 39(3). https://doi.org/10.14221/ajte.2014v39n3.4

Merriam, S. B. (Ed.). (1998). Qualitative research and case study applications in education: Revised and expanded from case study research in education. (2nd ed.). San Francisco, CA: Jossey-Bass Publishers.

Meuleman, A.-M., Garrett, R., Wrench, A., \& King, S. (2014). 'Some people might say I'm thriving but ... ': non-traditional students' experiences of university. International Journal of Inclusive Education, 19(5), 1-15. https://doi.org/10.1080/13603116.2014.945973

Mills, S., Yanes, M., \& Casebeer, C. (2009). Perceptions of distance learning among faculty of a college of education. Journal of Online Learning and Teaching, 5(1), 19-28. Retrieved from http://jolt.merlot.org/vol5no1/mills 0309.pdf

Muir, T., Milthorpe, N., Stone, C., Dyment, J., Freeman, E., \& Hopwood, B. (2019). Chronicling engagement: Students' experience of online learning over time. Distance Education, 40(2), 262-277. https://doi.org/10.1080/01587919.2019.1600367

NSW Education Standards Authority. (2018). Accreditation of initial teacher education programs in NSW: Policy and procedures. Sydney, Australia: NSW Government.

OECD. (2018). Education policy outlook 2018: Putting student learning at the centre. Paris, France: Author. https://doi.org/10.1787/9789264301528-en

O'Shea, S., Stone, C., \& Delahunty, J. (2015). "I 'feel' like I am at university even though I am online." Exploring how students narrate their engagement with higher education institutions in an online 
learning environment. Distance Education, 36(1), 41-58.

https://doi.org/10.1080/01587919.2015.1019970

Ottenbreit-Leftwich, A. T., Glazewski, K. D., Brush, T. A., Aslan, S., \& Zachmeier, A. (2018). Addressing technology integration concerns: Asynchronous video mentoring between pre-service teachers and exemplary technology-using in-service teachers. Australasian Journal of Educational Technology, 34(4), 1-15. https://doi.org/10.14742/ajet.3246

Ouzts, K. (2006). Sense of community in online courses. Quarterly Review of Distance Education, 7(3), 285-296. Retrieved from https://www.infoagepub.com/qrde-issue.html? $\mathrm{i}=\mathrm{p} 54 \mathrm{c} 3 \mathrm{ca} 4 \mathrm{dc} 8778$

Paechter, M., Maier, B., \& Macher, D. (2010). Students expectations of, and experiences in e-learning: Their relation to learning achievement and course satisfaction. Computers and Education, 54, 222229. https://doi.org/10.1016/j.compedu.2009.08.005

Pittaway, S. M., \& Moss, T. (2014). "Initially, we were just names on a computer screen": Designing engagement in online teacher education. Australian Journal of Teacher Education, 39(7), 140-156. https://doi.org/10.14221/ajte.2014v39n7.10

Ragusa, A. T., \& Crampton, A. (2017). Online learning: Cheap degrees or educational pluralization? British Journal of Educational Technology, 48(6), 1208-1216. https://doi.org/10.1111/bjet.12489

Restal, P., \& Laferrière, T. (2015). Digital equity and intercultural education. Education and Information Technologies, 20(4), 743-756. https://doi.org/10.1007/s10639-015-9419-z

Richardson. P, \& Watt, H. (2006). Who chooses teaching and why? Profiling characteristics and motivations across three Australian universities. Asia-Pacific Journal of Teacher Education, 34(1), 27-56. https://doi.org/10.1080/13598660500480290

SBS. (2018, August 18). Alarm bells sound over future teachers' low scores. SBS News. Retrieved from https://www.sbs.com.au/news/alarm-bells-sound-over-future-teachers-low-scores

Stacey, E., \& Wiesenberg. (2007). A study of face-to-face and online teaching philosophies in Canada and Australia. Journal of Distance Education, 22(1), 19-40. https://doi.org/10.1016/j.sbspro.2014.01.926

Stokes, R. (2018, September 20). How universities lower teacher standards by focusing on profit. The Sydney Morning Herald. Retrieved from https://www.smh.com.au/national/how-universities-lowerteacher-standards-by-focusing-on-profit-20180920-p504xg.html

Stone, C. (2012). Engaging students across distance and place. Journal of the Australian and New Zealand Student Services Association, 39(15), 49-55. Retrieved from https://www.anzssa.com/public/94/files/JANZSSA\%20editions/JANZSSA\%20April\%202012_Numb er 39.pdf

Stone, C., O'Shea, S., May, J., Delahunty, J., \& Partington, Z. (2016). Opportunity through online learning: experiences of first-in-family students in online open-entry higher education. Australian Journal of Adult Learning, 56(2), 146-169. Retrieved from https://www.ajal.net.au/2016-2/

Teacher Education Ministerial Advisory Group. (2014). Action now: Classroom ready teachers. Canberra, Australia: Department of Education and Training. Retrieved from https://docs.education.gov.au/node/36783

The Guardian. (2018, August 12). Coalition 'alarmed' after student with Atars as low as 17.9 accepted into teaching. Retrieved from https://www.theguardian.com/australia-news/2018/aug/12/coalitionalarmed-after-students-with-atars-as-low-as-179-accepted-into-teaching

Thomas, J., Barraket, J., Wilson, C., Cook, K., Louie, Y., Holcome-James, I., ... MacDonald, T. (2018). Measuring Australia's digital divide: The Australian digital inclusion index. https://doi.org/10.25916/5b594e4475a00

Thornton, H. (2013). Middle level professors' perspectives regarding online teacher education: Middle level teacher educators report their views of online teacher preparation. Middle School Journal, 44(4), 30-39. https://doi.org/10.1080/00940771.2013.11461862

Tomas, L., Lasen, M., Field, E., \& Skamp, K. (2015). Promoting online students' engagement and learning in science and sustainability preservice teacher education. Australian Journal of Teacher Education, 40(11). https://doi.org/10.14221/ajte.2015v40n11.5

Wood, D., Gray-Ganter, G., \& Bailey, R. (2016). Pre-commencement interviews to support transition and retention of first year undergraduate students. Student Success, 7(2), 21-31. https://doi.org/10.5204/ssj.v7i2.338

Wright, V. J. (2015). Is ATAR useful for predicting the success of Australian students in initial teacher education? Australian Journal of Teacher Education, 40(9). https://doi.org/10.14221/ajte.2015v40n9.1

Yin, R. (2018). Case study research and applications: Design and methods. Thousand Oaks, CA: Sage. 
Corresponding author: Rebecca Walker, Rebecca.M.Walker@curtin.edu.au

Copyright: Articles published in the Australasian Journal of Educational Technology (AJET) are available under Creative Commons Attribution Non-Commercial No Derivatives Licence (CC BY-NC-ND 4.0). Authors retain copyright in their work and grant AJET right of first publication under CC BY-NC-ND 4.0 .

Please cite as: Pelliccione, L., Morey, V., Walker, R., \& Morrison, C. (2019). An evidence-based case for quality online initial teacher education. Australasian Journal of Educational Technology, 35(6), 64-79. https://doi.org/10.14742/ajet.5513 